\title{
Güneydoğu Anadolu Bölgesi’ndeki aylık toplam tava buharlaşma verilerinin Mann-Kendall Testi ve Yenilikçi Şen Yöntemi ile trend analizi
}

\author{
Trend analysis of monthly total pan evaporation data of Southeast Anatolia Region with \\ Mann-Kendall Test and Innovative Sen Method
}

\author{
Yavuz AVŞAROĞLU*1,a, Veysel GÜMÜŞŞ,b, Oğuz ŞİMŞEK ${ }^{1, \mathrm{c}}$, Latif DİNSEVER ${ }^{1, \mathrm{~d}}$, ,Mehmet KUŞ,e $^{2, \mathrm{e}}$ \\ ${ }^{I}$ Harran Üniversitesi, Mühendislik Fakültesi, İnşaat Mühendisliği Bölümü, 63050, Şanlıurfa \\ ${ }^{2}$ Harran Üniversitesi, Teknik Bilimler MYO, Elektrik Bölümü, 63250, Şanlıurfa
}

• Geliş tarihi / Received: 02.04.2021 • Düzeltilerek geliş tarihi / Received in revised form: $21.06 .2021 \quad$ • Kabul tarihi / Accepted: 05.07.2021

Öz

Buharlaşma miktarındaki değişimin doğru bilinmesi, su kaynaklarının yönetimi, su ile ilgili yapıların tasarlanması ve su eylem planlarının hazırlanması için önemlidir. Bu çalışmada, Türkiye'nin önemli tarımsal alanlarını barındıran Güneydoğu Anadolu Bölgesi'ndeki Gaziantep, Şanlıurfa ve Mardin istasyonlarına ait aylık toplam tava buharlaşması verilerinin trendleri, parametrik olmayan Mann-Kendall (MK) testi ve Yenilikçi Şen Yöntemi (Innovative Trend Analysis-ITA) ile, lineer trend eğimleri ise Sen'in trend eğim metodu ile belirlenmiştir. Çalışma sonucunda, MK testine göre hesaplanan değerlere göre anlamlı trend sadece Şanlıurfa istasyonunda, mayıs ve eylül aylarında \%95 güven aralığında, ekim ayında ise \%90 güven aralığında artan yönde belirlenmiş ve bu istasyonda lineer trend eğim değerlerine göre en yüksek artış miktarı mayıs ayında \%0.98/yıl olarak hesaplanmıştır. ITA yöntemiyle yapılan hesaplar sonucunda düşük, orta ve yüksek değerlerde trend varlığına rastlanmıştır. ITA yönteminin hesaplama kolaylığı, sonuçları grafiksel olarak verme yeteneği ile monotonik trend analizi yöntemlerine alternatif olarak kullanılabileceği sonucuna varılmıştır.

Anahtar kelimeler: Güneydoğu Anadolu Bölgesi, Mann-Kendall, Tava buharlaşması, Trend analizi, Yenilikçi Şen Yöntemi

\begin{abstract}
Determining the change in the amount of evaporation is important for water resources management, design of water structures and preparing water action plans. In this study, trends of total monthly pan evaporation data for Gaziantep, Şanlurfa and Mardin stations located as Southeastern Anatolia Region, which is important agricultural area of Turkey, are carried out using non-parametric Mann-Kendall (MK) and Innovative Trend Analysis (ITA) methods. The linear trend slope is determined with Sen's slope method. As a result of the study, the significant increasing trend is found with MK test in May and September at 95\% confidence level and in October at 90\% confidence level. The highest increase in this station according to the linear trend slope values is calculated 0.98\%/year. As a result of analysis with ITA method, there is a trend occurrence in low, medium, and high values. It is concluded that ITA method can be used as an alternative method to monotonic trend analysis methods, since its ease of calculation and its ability to give results graphically.
\end{abstract}

Keywords: Southeastern Anatolia Region, Mann-Kendall, Pan evaporation, Trend analysis, Innovative trend analysis

\footnotetext{
*a Yavuz AVŞAROĞLU; yavsaroglu@ harran.edu.tr, Tel: (0414) 31830 00, orcid.org/ 0000-0003-0920-3202

${ }^{\mathrm{b}}$ orcid.org/0000-0003-2321-9526 $\quad{ }^{\mathrm{c}}$ orcid.org/0000-0001-6324-0229 $\quad{ }^{\mathrm{d}}$ orcid.org/0000-0001-8573-1539

${ }^{\mathrm{e}}$ orcid.org/0000-0003-2215-9250
} 


\section{Giriş}

Hidrolojik çevrimin önemli elemanlarından biri olan buharlaşma; tarım, ormancılık, ekoloji gibi farklı uygulama alanlarında kullanılmaktadır. Buharlaşma kısaca sıvı haldeki suyun su buharı formuyla tekrar atmosfere transferi olarak tanımlanmaktadır (Bruton vd., 2000). Meydana gelen buharlaşmanın doğru bir şekilde bilinmesi, su kaynaklarının planlaması ve su yapılarının işletilmesinde oldukça önemlidir. Buharlaşma miktarını ölçmek için buharlaşma tavaları kullanılmaktadır. Buharlaşma tavaları, basit ve düşük maliyetli bir şekilde buharlaşan su miktarının ölçümünü sağlar. Buharlaşma tavalarının, buharlaşma üzerinde etkili olan birçok fiziksel etkiyi bünyesinde bulundurmaları gibi bir avantajı vardır. Tava buharlaşması üzerine yapılan araştırmalar uzun y1llar boyunca hidrometeorolojik değişikliklere inceleyen çalışmalara konu olmuştur (Singh vd., 2020). Bir bölgede meydana gelen buharlaşma miktarını en çok etkileyen meteorolojik parametrelerin başında, güneşlenme şiddeti, sıcaklık, nem (buhar basıncı) ve rüzgâr hızı gelmektedir.

Buharlaşma, potansiyel buharlaşma $\left(\mathrm{ET}_{0}\right)$, tava buharlaşması $\left(\mathrm{ET}_{\mathrm{pan}}\right)$ ve gerçek buharlaşma olarak sınıflandırılmaktadır. Potansiyel buharlaşma, Brutsaert (1982) tarafindan, enerjinin tek sinırlayıc1 faktör olması durumunda meydana gelen buharlaşma olarak ifade edilirken, gerçek buharlaşma, büyük bir bölgedeki ortalama buharlaşma olarak tanımlanır. Atmosferdeki nem miktarı buharlaşmayı sınırlandıran bir faktör olabileceğinden, gerçek buharlaşma genellikle potansiyel buharlaşmadan daha az olacaktır. Tava buharlaşması, buharlaşma tavasından ölçülen ve bir azaltma faktörü ile çarpılarak elde edilen buharlaşma tahminlerini ifade eder. Tava buharlaşmasından, özellikle bir rezervuar tasarlanırken su bütçesinin hesaplanmasında yararlanılmaktadır.

Küresel 1sınma, daha yüksek buharlaşmaya sebebiyet vermektedir. Böylece, hidrolojik döngü hizlanmakta ve bu durum su kaynaklarının düzensiz dağılımına neden olmaktadır. Tüm bunların bir sonucu olarak daha yüksek miktarda su buharı atmosfere taşınmaktadır (Menzel ve Bürger, 2002). Küresel ısınmanın son 50 yılda Dünya'nın yüzey sıcaklığının yıllık $0.013^{\circ} \mathrm{C}$ civarında arttırdığ 1 bilinmektedir (IPCC, 2007). İklim değişikliğinin hidrolojik ve meteorolojik parametreler üzerindeki etki miktarının, tava buharlaşmasındaki değişimlerin gözlemlenerek belirlenebileceği birçok araştırmacı tarafindan bildirilmiştir (Jung vd., 2010; Oguntunde vd., 2012). Bu nedenle, hidrolojik çevrimde meydana gelmesi muhtemel değişiklikler hakkında daha doğru yaklaşımlar geliştirebilmek için, tava buharlaşmasının zamansal değişimlerinin değerlendirilmesi önemlidir. Buharlaşma miktarındaki değişimlerin hesaplanmasıyla olası kayıplarının doğru tahmin edilmesi, özellikle su kıtlığ çeken bölgelerde mevcut su kaynaklarının yönetiminde, bu değişimlerin büyüklüğüneyönüne göre yeni yapı türünün seçimi veya farklı eylem planları hazırlanması hayati bir rol oynamaktadır (Hassan vd., 2018).

Bir zaman serisi değişiminin belirlenmesi için en çok başvurulan yollardan bir tanesi ise trend analizidir. Trend analizinde, veri setinde istatistiksel olarak anlamlı bir değişim olup olmadığ 1 belirlenmekte ve meydana gelen değişimin miktarı da hesaplanabilmektedir. Ele alınan zamansal veri setinin bir matematiksel dağılıma uyması zorunluluğu bulunmamasından dolay1, monotonik trendler değerlendirilirken parametrik olmayan testler ve özellikle MannKendall testi (MK) yoğunlukla kullanılmaktadır (Asadi ve Karami, 2021; Chen vd., 2016; Sayyad vd., 2019). Monotonik trend analizi yöntemleri sadece trend mevcudiyeti belirlemekte, ancak zamansal değişimlerin hangi veri aralığında olduğu ise bilinememektedir. Şen (2012) tarafindan önerilen ve literatürde çoğunlukla Innovative Trend Analysis (ITA) yöntemi olarak adlandırılan Yenilikçi Şen Yöntemi ise zamansal veri setinin hangi veri aralığında (düşük, orta ve yüksek) tarihsel bir değişim sergilediğini belirlemektedir. Hidro-metorolojik verilerin trendini belirlemede son yıllarda MK ve ITA yöntemleri sıklıkla tercih edilmektedir. Örneğin, Mann-Kendall ve ITA yöntemlerini kullanarak Wu ve Qian (2017) yağış verilerinin, Tosunoglu ve Kisi (2017) kuraklık değerlerinin, Nourani vd. (2018) yağış, akım, sicaklık, nem verilerinin, Alashan (2020) sicaklık değerlerinin, Kuriqi vd. (2020) akım değerlerinin ve Alifujiang vd. (2021) akış verilerinin trend analizini gerçekleştirmişlerdir. Buradan da görüleceği üzere bu yöntemler çeşitli hidrometeorolojik verilerin trendlerinin belirlenmesinde tercih edilmiştir. Dünya genelinde buharlaşma trendi ile ilgili gerçekleştirilen çeşitli çalışmalar incelendiğinde, aynı şekilde bu yöntemlerin sık bir şekilde bir arada kullanıldığ 1 görülmektedir. MK ve ITA metotları kullanılarak gerçekleştirilen çalışmalarda; Burn ve Hesch (2007) Kanada'daki 30-50 y1 arasında veri aralığına sahip 55 istasyonda buharlaşma trendini MK yöntemi ile incelemiş, çalışma bölgesinin kuzeyinde artan trendlere, güneyinde ise azalan trendlerin 
olduğunu, kuzey tarafinda gerçekleştirilen buharlaşmadaki artışın rüzgâr hızına, güney bölgesinde gerçekleşen azalmanın ise buhar basıncında oluşan eksikliğe bağlı olduğunu belirtmiştir. Jhajharia vd. (2009) Hindistan'da 11 şehirde, Limjirakan ve Limsakul (2012) Tayland'daki 28 istasyona ait 1970-2007 verilerini kullanarak MK yöntemi ile buharlaşma trendlerini çalışmışlardır. Parametrik olmayan Mann-Kendall veya ITA yöntemleri ile ülkemizde yapılan buharlaşma trendi konusunu içeren çalışmalar incelendiğinde; Aydın ve Topaloğlu (2010) Türkiye'nin genelini 1975-2006 yılları arasındaki verileri kullanarak, Topaloğlu ve Özfidaner (2012) Türkiye genelinde farklı istasyonlara ait 1975-2006 yıllarındaki verileri kullanarak, Yeşilırmak (2013) Büyük Menderes Havzasında bulunan 15 farklı istasyona ait verileri kullanarak, Kisi (2015) Güneydoğu'daki 6 farklı istasyona ait 1970-2010 yıllarında kaydedilen verileri kullanarak, Kale (2017) 1971-2011 yılları arasındaki verileri kullanarak Çanakkale istasyonunda oluşan, Çıtakoğlu vd. (2017) Ege Bölgesi’nin 1971-2014 yıllarında meydana gelen, Bacanlı ve Tanrıkulu (2017) Ege Bölgesinde bulunan 25 istasyonda elde edilen verileri kullanarak, Bacanlı ve Çukurluoğlu (2018) Antalya istasyonunda 1965-2017 y1llar1 arasındaki verileri kullanarak, Sandalc1 (2019) Sapanca Gölü'nde meydana gelen, Arslan (2019) Kapadokya bölgesinin, Bağdatlı ve Arıkan (2020) Niğde istasyonunda ve Yagbasan vd. (2020) Ankara'daki Mogan ve Eymir Gölü'ne ait 19972015 arasındaki verileri kullanarak Türkiye'deki çeşitli bölgelerdeki buharlaşmanın trendlerini belirlemişlerdir.

Bu çalışma kapsamında, Türkiye'nin birçok önemli su yapısını ve önemli tarımsal alanlarını barındıran Güneydoğu Anadolu Bölgesi'ndeki Gaziantep, Şanlıurfa ve Mardin istasyonlarına ait aylık toplam tava buharlaşması verilerinin trendleri parametrik olmayan Mann-Kendall ve ITA yöntemleriyle, doğrusal trend eğimleri ise Sen'in trend eğim metodu ile belirlenmiş ve detaylı bir değerlendirme yapılmıştır.

\section{Materyal ve metot}

\section{1. Çalışma alanı}

Bu çalışmada, Güneydoğu Anadolu Bölgesi'nde yer alan üç komşu il olan Gaziantep, Şanlıurfa ve Mardin illerindeki meteorolojik istasyonlarda ölçülen aylık toplam buharlaşma verileri kullanılmıştır (Şekil 1). Çalışma alanındaki iller, yüzölçümü olarak bölgenin \%46'sına denk gelirken, nüfus olarak da bölgenin \%56'sını oluşturmaktadır (TÜİK, 2020). Bu bölge tarım alanı olarak Türkiye için çok önemli bir konumda olup, söz konusu üç il de Güneydoğu Anadolu Projesi (GAP) kapsamında bulunmaktadır. Ülkemizde Devlet Su İşleri (DSI) ve Meteoroloji Genel Müdürlüğü (MGM) tarafindan yapılan buharlaşma ölçümlerinde Class A tipi buharlaşma tavaları kullanılmakta ve gerçek buharlaşma değerlerinin hesaplanmasında buharlaşma katsayısı 0.7 kabul edilmektedir. Çalışmada kullanılan veriler Şanlıurfa için 1978-2015, Gaziantep ve Mardin istasyonları için ise 19752015 arasında ölçülmüş olup, istasyonlar hakkındaki bilgiler ve ölçüm yapılan aylara göre aylık toplam buharlaşma miktarlarının ortalama miktarları Tablo 1'de verilmiştir. Buna göre, en yüksek aylık toplam buharlaşma miktarlarının ortalaması tüm istasyonlar için temmuz ayında belirlenirken, en düşük ortalama buharlaşma değeri ise Şanlıurfa için nisan, Gaziantep ve Mardin istasyonlarında ise ekim ayında olmuştur. Gaziantep ve Mardin istasyonlarında nisan ayına ait ölçüm olmadığından değerlendirmeye alınmamıştır.

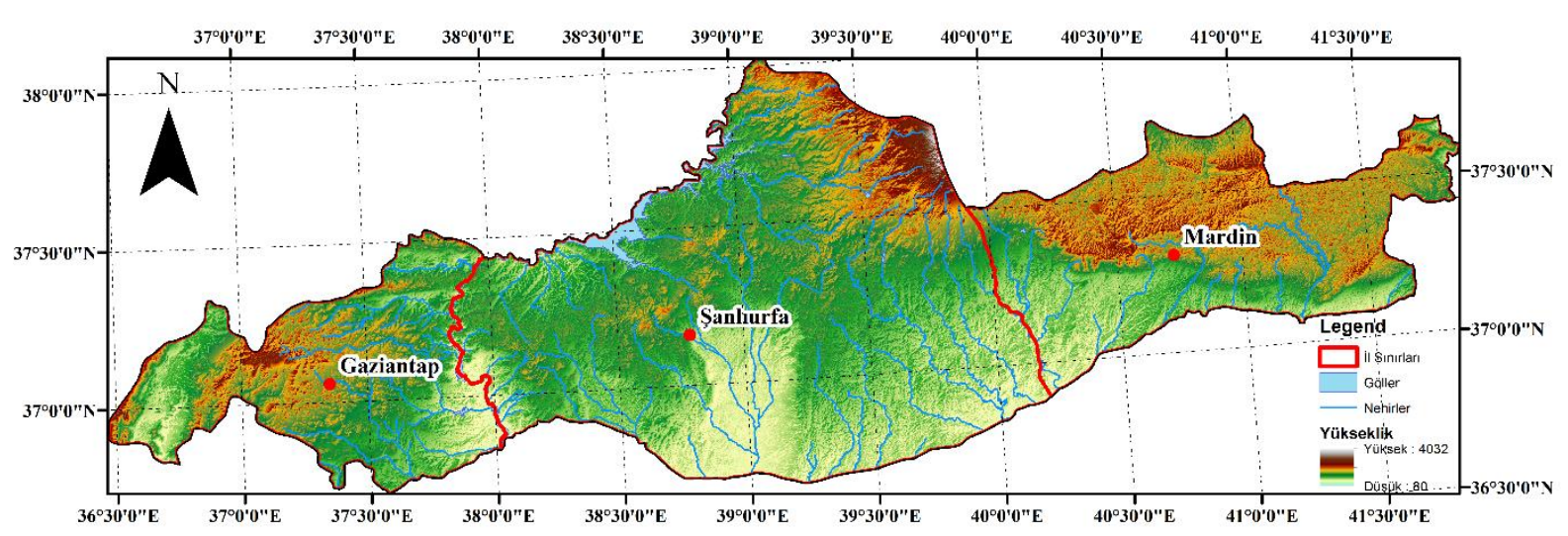

Şekil 1. Çalışma alanı 
Tablo 1. İstasyonlara ait bilgiler ve aylık toplam buharlaşma miktarlarının ortalaması

\begin{tabular}{|c|c|c|c|c|c|c|c|c|c|c|}
\hline \multirow{2}{*}{$\begin{array}{l}\text { İstasyon } \\
\text { adı }\end{array}$} & \multirow{2}{*}{$\begin{array}{l}\text { İstasyon } \\
\text { no }\end{array}$} & \multirow{2}{*}{ Koordinatlar } & \multirow{2}{*}{$\begin{array}{l}\text { Veri } \\
\text { aralığ } 1\end{array}$} & \multicolumn{7}{|c|}{$\begin{array}{c}\text { Ölçüm yapılan aylara göre toplam buharlaşma miktarları ortalaması } \\
(\mathbf{m m})\end{array}$} \\
\hline & & & & Nisan & Mayıs & Haziran & Temmuz & Ağustos & Eylül & Ekim \\
\hline Gaziantep & 17261 & $\begin{array}{l}37.0585 \mathrm{~K} \\
37.3510 \mathrm{D}\end{array}$ & $\begin{array}{l}1975- \\
2015\end{array}$ & & 169.03 & 243.25 & 293.86 & 268.99 & 187.65 & 103.18 \\
\hline Şanlıurfa & 17270 & $\begin{array}{l}37.1608 \mathrm{~K} \\
38.7863 \mathrm{D}\end{array}$ & $\begin{array}{l}1978- \\
2015\end{array}$ & 107.35 & 177.31 & 267.97 & 322.06 & 286.62 & 201.36 & 115.85 \\
\hline Mardin & 17275 & $\begin{array}{l}37.3103 \mathrm{~K}, \\
40.7284 \mathrm{D}\end{array}$ & $\begin{array}{l}1975- \\
2015\end{array}$ & & 245.01 & 397.43 & 493.48 & 485.24 & 373.99 & 206.29 \\
\hline
\end{tabular}

Ele alınan istasyonlara ait ölçülmüș değerlerin kutu grafikleri Şekil 2'de verilmiştir. Buna göre, Şanlıurfa ve Gaziantep istasyonlarının verilerinde ortalama değer ile medyan değerlerin yakın olduğu, ayrıca en büyük ve en küçük değerin çeyrekler açıklığa (The Interquartile Range-IQR) oldukça yakın olduğu, yani aykırı değer olmadıkları değerlendirilebilir. Ancak, Mardin istasyonunda ölçülmüş olan buharlaşma değerleri diğer iki istasyona göre oldukça büyük olduğu, ayrıca Mardin istasyonunda özellikle en büyük değerlerin çeyrekler arası aralığın oldukça dışına çıktığı, yani aykırı değer olduğu görülmektedir.

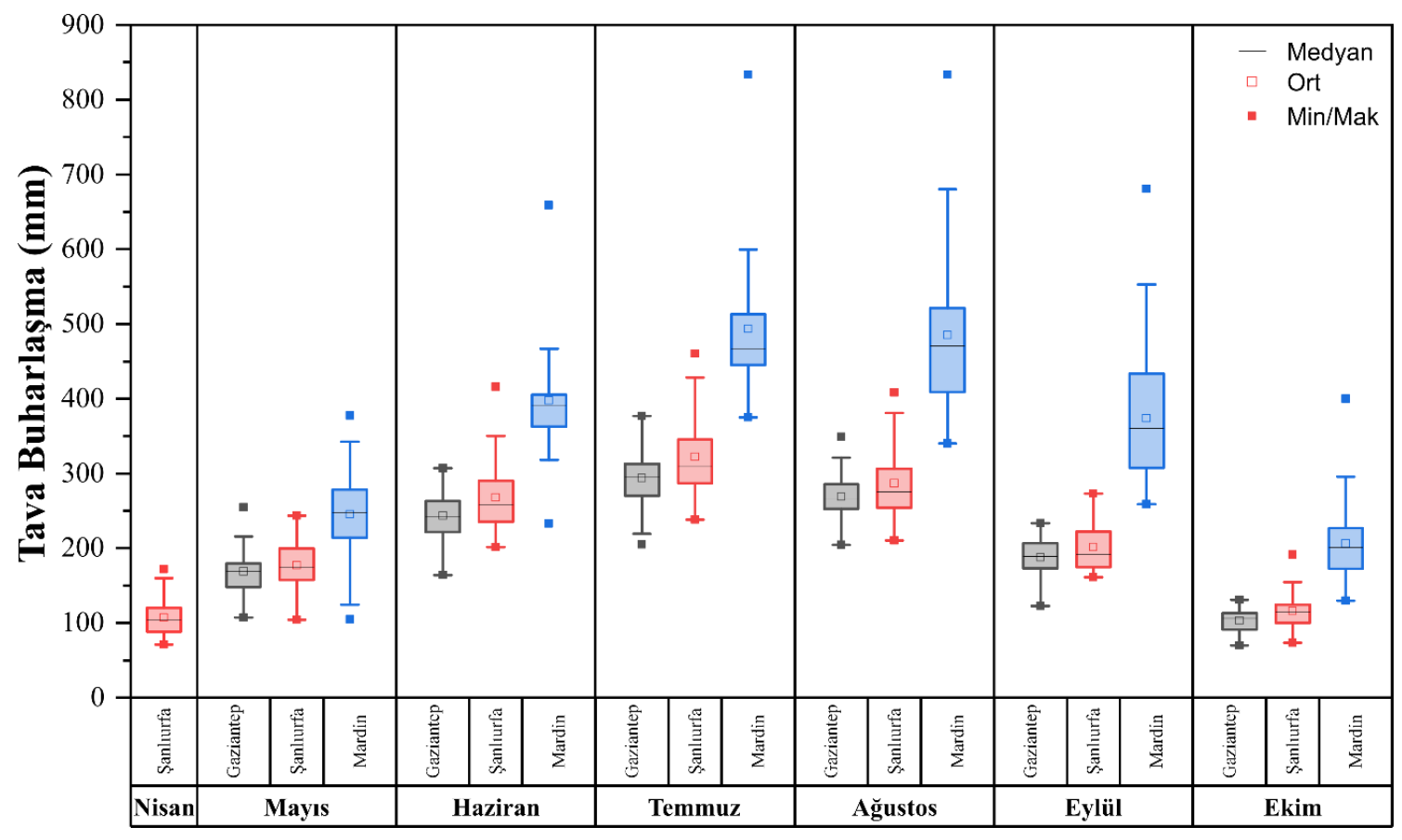

Şekil 2. Ölçülmüş olan tava buharlaşma değerlerinin kutu grafikleri

\subsection{Mann-Kendall testi}

Monotonik bir test olarak değerlendirilen MannKendall testi, hidro-meteorolojik verilerde istatistiksel olarak anlamlı trend olup olmadığını belirlemek için sıklıkla kullanılan parametrik olmayan bir testtir (Kendall, 1948; Mann, 1945). $\mathrm{Bu}$ test ile bir zaman serisindeki trend varlığ $\breve{1}$ " $\mathrm{H}_{0}$ : trend yok" (sifir hipotezi) ile kontrol edilmektedir (Yenigün vd., 2008). Buna göre, test istatistiği $S$ ve işaret fonksiyonu Denklem 1 ve 2 'de verildiği gibi hesaplanır. Daha sonra, Denklem 3 ve 4 'te verilen formüller ile sirasiyla $S$ 'in varyansı ve $Z$ test istatistiği belirlenir.

$$
\begin{aligned}
& S=\sum_{i=1}^{n-1} \sum_{j=i+1}^{n} \operatorname{sign}\left(x_{j}-x_{i}\right) \\
& \operatorname{sign}\left(x_{j}-x_{i}\right)= \begin{cases}+1 & x_{j}>x_{i} \\
0 & x_{j}=x_{i} \\
-1 & x_{j}<x_{i}\end{cases} \\
& \operatorname{var}(S)=\left[n(n-1)(2 n+5)-\sum_{i=1}^{m} t_{i} i(i-1)(2 i+5)\right] / 18
\end{aligned}
$$


$Z=\left\{\begin{array}{cc}\frac{S-1}{\sqrt{\operatorname{var}(S)}} & S>0 \\ 0 & S=0 \\ \frac{S+1}{\sqrt{\operatorname{var}(S)}} & S<0\end{array}\right.$

Burada, $n$ veri sayısını, $x$ ise $i \quad$ ve $j$ zamanlarındaki veriyi, $t_{i}$ değeri $i$ uzunluğundaki bir seride tekrarlanan gözlemleri göstermektedir.

İstatistiksel olarak anlamlı bir trendin belirlenmesi için $Z$ değeri kullanılır. $\alpha$ anlamlılık düzeyinde $|Z|<Z_{\alpha / 2}$ olması durumunda anlamlı bir trend olmadığı, $\quad|Z| \geq Z_{\alpha / 2}$ olması durumunda ise istatistiksel olarak anlamlı bir trend olduğundan söz edilir. Bunun yanında, $S$ değerinin işaretine göre de trendin artan ( $S$ değeri pozitif) ya da azalan yönde ( $S$ değeri negatif) olduğu sonucuna varilir.

\subsection{Yenilikçi Şen Yöntemi (Innovative Trend Analysis-ITA)}

Monotonik trend, bir zaman serisindeki " $\mathrm{H}_{0}$ :Trend Yok" hipotezinin kabulü ya da reddi sonucunu vermekte, ancak trendin lineer olup olmadığı ile ilgili bilgi vermemektedir. Monotonik trend analizi yöntemlerinin eksik kaldığı bu noktada Şen (2012) tarafından önerilmiş olan Yenilikçi Şen Yöntemi (Innovative Trend Analysis-ITA), bir zaman serisindeki verilerin düşük, orta ya da yüksek değerlerinin trendinin olup olmadığı ile ilgili değerlendirme yapma imkanını ortaya koymaktadır. ITA yönteminde, veri seti ölçüm tarihine göre sıralanarak iki eşit parçaya bölünür ve bu iki veri seti küçükten büyüğe doğru sıralanır. Sıralanmış verilerin ilki (y1) x eksenine, ikincisi (y2) ise y eksenine yerleştirilerek bunların saçılım grafiği oluşturulur. Örneği Şekil 3'te verilmiş olan bu grafik üzerine $1: 1\left(45^{\circ}\right)$ ve bu çizgiye paralel, $\pm \% 5$ ve $\pm \% 10$ çizgileri yerleştirilerek verilerin bu çizgilere göre dağılımları yorumlanır. Buna göre, eğer veriler $1: 1$ çizgisinin $\pm \% 5$ arasında ise "trend yok", \%5-10 aralığında ise "trend var", \%10 çizgisinin dişında ise "güçlü trend var" denilmektedir (Caloiero, 2020). Trend yönü de yine 1:1 çizgisine göre değerlendirilir. Ĕ̆ger veriler $1: 1$ çizgisinin üstünde ise artan yönde, altında ise azalan yönde trend şeklinde yorumlanır. Bu yöntemde her bir veri aralığı için değerlendirme yapmak mümkünken, genellikle veri seti düşük, orta ve yüksek değer olarak ayrilarak değerlendirme üç kategori için yapılmaktadır (Alifujiang vd., 2020; Ay ve Kisi, 2015; Boudiaf vd., 2021).

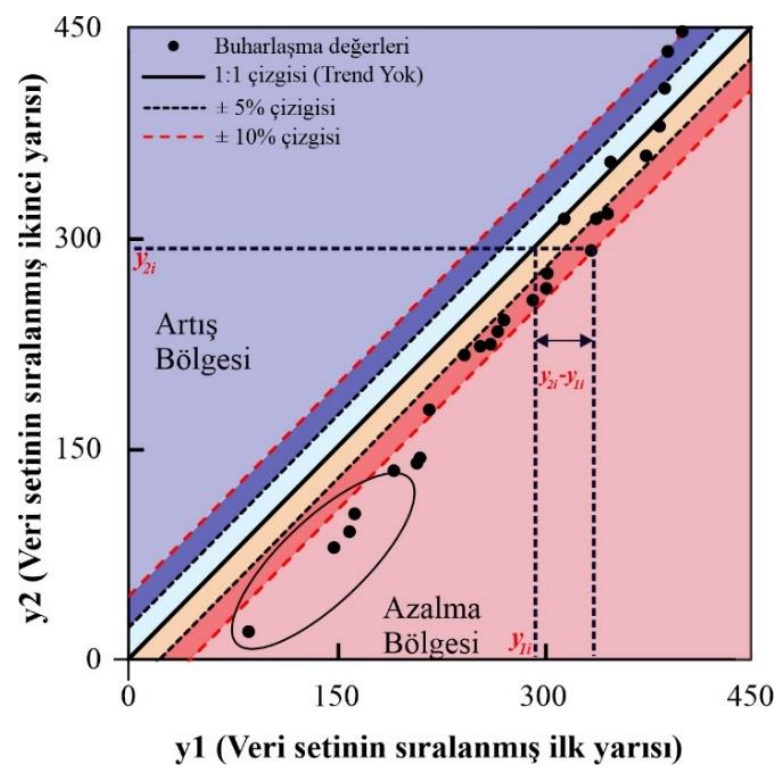

Şekil 3. ITA'ya göre trend oluşma durumu

ITA yönteminde sıralanmış iki veri setinin değerleri ile trend göstergesi $D$ değeri Denklem 5 'teki gibi hesaplanır.

$$
D=\frac{1}{n} \sum_{i=1}^{n} 10 \frac{\left(y_{1 i}-y_{2 i}\right)}{\overline{y_{1}}}
$$

Burada, $D$ 'nin işareti trendin yönünü (pozitif ise artan, negatif ise azalan), $n$ her bir alt serideki veri 
sayısını, $\bar{y}_{1}$ ise ilk alt serinin ortalamasını ifade etmektedir. Burada, hesaplanan $D$ değerini MK testi ile karşılaştırmak için $D$ değeri 10 ile çarpılmaktadır (Nisansala vd., 2020; Wu ve Qian, 2017)

\subsection{Sen'in trend eğim metodu}

Parametrik olmayan bir test ile zaman serisinin lineer değişimi, yani eğiminin belirlenmesi amaçlanmaktadır (Sen, 1968). Bu yöntemde $Q_{i}$ Denklem 6'da verilmiş olan bağıntı ile hesaplanır.

$Q_{i}=\left(x_{j}-x_{k}\right) /(j-k)(i=1, \ldots, N)$

Burada, veri sayısı $N, j$ ve $k$ zamanlarındaki veriler $x_{j}$ ve $x_{k}^{\prime}$ 'dır. Elde edilen $Q_{i}$ değerleri, küçükten büyüğe doğru sıralanır ve medyan değeri alınır. Alınan $Q_{\text {medyan }}$ ise ilgili gözlemlerin birim zamandaki değişimi olarak değerlendirilir. Hesaplanan $Q_{\text {medyan }}$ değerinin pozitif olması artan yönde, negatif olması ise azalan yönde bir trendin olduğunu gösterir.

\section{Bulgular ve tartışma}

Hidro-meteorolojik verilerin Mann-Kendall testi öncesi iç bağımlılığının kontrol edilmesi ve iç bağımlılık varsa bunun giderilmesi gerekmektedir (Gumus, 2019; Yenigün vd., 2008). Bu amaçla çalışma kapsamında ele alınan istasyonların iç bağımlılığın kontrolü için, Salas (1980) tarafindan önerilmiş ve detayları Gumus (2019)'da görülebilecek olan yöntem kullanılmıştır. Bu yöntemde hesaplanan değerlerin Şekil 4'te Lag-1 (bir ay gecikmeli) korelasyon katsayısı kesikli çizgiler ile gösterilen aralıkta kalması durumunda iç bağımlılık olmadığı ve verilerin olduğu gibi kullanılması anlamına gelmektedir. Ancak, eğer kesikli çizginin dışında bir durum meydana gelecek olur ise "pre-whitening" yöntemi ile verilerin iç bağımlılık etkisinin giderilmesi gerekmektedir. "Pre-whitening" yönteminde veri setinin Lag-1 korelasyon katsay1s1 $\mathrm{r}_{1}\left(\mathrm{x}_{2}-\mathrm{r}_{1} \mathrm{x}_{1}, \mathrm{x}_{3}-\mathrm{r}_{1} \mathrm{x}_{2}, \ldots, \mathrm{x}_{\mathrm{n}}-\right.$ $\left.r_{1} X_{n-1}\right)$ işlemi yapılarak yeni bir zaman serisi elde edilmektedir. Bu yaklaşım ile tüm istasyonların ele alınan ayları için Lag-1 korelasyon katsayısı ve Salas (1980)'e göre hesaplanmış aralıklar Şekil 4'te verilmiştir. Buna göre, Şanlıurfa ve Gaziantep istasyonlarında ekim ayı dışındaki tüm aylarda pozitif bir iç bağımlılık görülürken, Mardin istasyonunda ise sadece mayıs ayında iç bağımlılık etkisi görülmüştür. $\mathrm{Bu}$ nedenle, belirtilen ilgili aylarda pre-whitening yöntemi uygulanarak yeni zaman serileri elde edilmiş ve Mann-Kendall yöntemi yeni verilere uygulanarak trend analizi yapılmıştır.

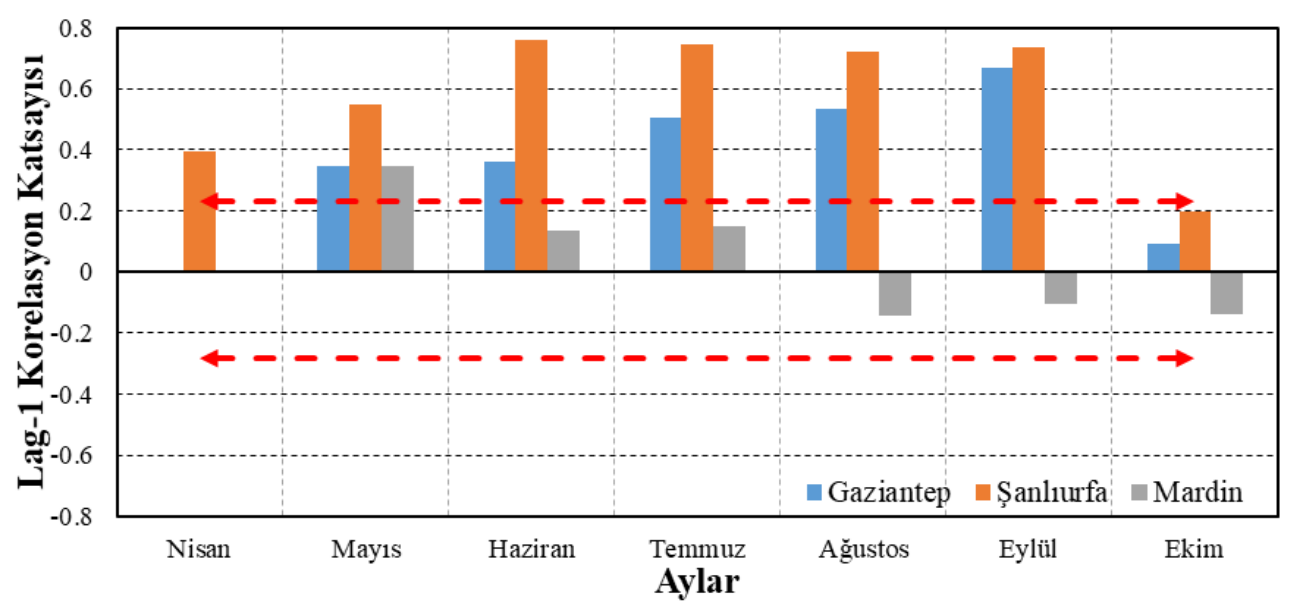

Şekil 4. Çalışılan istasyon verilerinin Lag-1 korelasyon katsayısı dağılımı

Parametrik olmayan MK yöntemi ile elde edilen $Z$ değerleri ve Sen'in trend eğim yöntemi ile hesaplanan trend eğimleri Tablo 2'de verilmiştir. Tablodaki değerlerden görüldüğü üzere, buharlaşma ölçülen istasyon ve ayların büyük bir çoğunluğunda artan yönde bir trend tespit edilmiştir. Sadece, Mardin istasyonunda mayıs ayında ise azalan yönde bir trend tespit edilmiştir. Trend analizi yapılan istasyonlarda MK yönteminde elde edilen $Z$ değerleri $\% 90$ ve $\% 95$ güven aralığında anlamlı trend varlığı ise Gaziantep ve Mardin'de hiçbir ayda tespit edilememiştir. Şanlıurfa istasyonunda ise mayıs ve eylül aylarında $\% 95$, ekim ayında ise $\% 90$ güven aralığında artan yönde anlamlı trend varlığı belirlenmiştir. Tabloda trend eğimleri ise iki türlü verilmiştir; birincisi $\mathrm{mm} / \mathrm{y} 11$, diğeri ise $\% / \mathrm{y} 11$ değerinin uzun yıllar ortalama değere bölünüp 100 ile çarpılması ile elde edilmiş olan \%/yıl değeridir. $\% / y 1 l$ değerinin verilmesinin nedeni, istasyonların 
birbirleri ile kıyaslanmasının sağlanmasıdır. Eğim değerlerinde ise anlamlı trend görülen Şanlıurfa istasyonunda artış miktarı mayıs ayında $\% 0.98 / \mathrm{y} 11$, eylül ayında, $\% 0.72$ ve ekim ayında $\% 0.53 /$ yıl şeklinde olmuştur. En yüksek değişim ise $\mathrm{mm} / \mathrm{y} 1 \mathrm{l}$ olarak Şanlıurfa istasyonunda temmuz ayında görülmüş, ancak \%/yıl cinsinden Şanlıurfa istasyonunda haziran ayında meydana gelmiştir. Anlamlı trend belirlenmeyen Gaziantep ve Mardin istasyonlarında ise artış sınırlı olmuş ve değeri $\% 0.08-\% 0.35 \mathrm{~mm} / \mathrm{y} 1 \mathrm{l}$ aralığında olmuştur.

Tablo 2. Mann-Kendall ve trend eğim değerleri

\begin{tabular}{|c|c|c|c|c|c|c|c|c|c|}
\hline \multirow[b]{2}{*}{ Ay/İstasyon } & \multicolumn{3}{|c|}{ Gaziantep } & \multicolumn{3}{|c|}{ Şanlıurfa } & \multicolumn{3}{|c|}{ Mardin } \\
\hline & $\mathbf{Z}$ & $\begin{array}{c}\text { Eğim } \\
(\mathrm{mm} / \mathrm{yıl})\end{array}$ & $\begin{array}{c}\text { Eğim } \\
(\% / y ı l)\end{array}$ & $\mathbf{Z}$ & $\begin{array}{c}\text { Ĕgim } \\
(\mathrm{mm} / \mathrm{yıl})\end{array}$ & $\begin{array}{c}\text { Eğim } \\
(\% / y ı l)\end{array}$ & $\mathbf{Z}$ & $\begin{array}{c}\text { Ĕgim } \\
(\mathrm{mm} / \mathrm{yll})\end{array}$ & $\begin{array}{c}\text { Eğim } \\
(\% / y ı l)\end{array}$ \\
\hline Nisan & & & & 1.0855 & 0.96 & $\% 0.89$ & & & \\
\hline Mayıs & 0.8505 & 0.6 & $\% 0.35$ & $2.2103 * *$ & 1.73 & $\% 0.98$ & -0.6641 & -0.53 & $-\% 0.22$ \\
\hline Haziran & 0.734 & 0.79 & $\% 0.32$ & 1.1902 & 2.97 & $\% 1.11$ & 0.6402 & 0.32 & $\% 0.08$ \\
\hline Temmuz & 0.4777 & 0.3 & $\% 0.10$ & 1.0071 & 3.12 & $\% 0.97$ & 0.7638 & 0.53 & $\% 0.11$ \\
\hline A ğustos & 0.3146 & 0.43 & $\% 0.16$ & 1.321 & 2.31 & $\% 0.81$ & 1.4938 & 1.61 & $\% 0.33$ \\
\hline Eylül & 0.5243 & 0.57 & $\% 0.30$ & $2.0272 * *$ & 1.44 & $\% 0.72$ & 0.6402 & 0.75 & $\% 0.20$ \\
\hline Ekim & 0.7076 & 0.17 & $\% 0.16$ & $1.7476 *$ & 0.61 & $\% 0.53$ & 0.5279 & 0.33 & $\% 0.16$ \\
\hline
\end{tabular}

\%90 güven aralığl, **\%95 güven aralığı

MK testi ile monotonik trendler belirlendikten sonra, ITA yöntemi kullanılarak Gaziantep, Şanlıurfa ve Mardin istasyonlarına ait aylık toplam tava buharlaşma değerlerinin trendleri belirlenmiş ve elde edilen sonuçlar Şekil 5, 6 ve 7'de verilmiştir. $\mathrm{Bu}$ kısımda, aylık toplam tava buharlaşma değerleri düşük, orta ve yüksek değerler olarak üç ayrı aralık için değerlendirilmiştir. Düşük değerler için, Gaziantep istasyonunda, sadece eylül ayında güçlü bir azalan trend gözlemlenirken, diğer aylarda anlamlı değişim tespit edilememiştir. Şanlıurfa istasyonunda mayıs ayında güçlü artış trendi, haziran ve temmuz aylarında ise artış trendi tespit edilmiştir. Mardin istasyonunda ise sadece mayıs ve haziran aylarında bir azalma trendi görülmüştür.
Orta değerlere göre, Gaziantep'te herhangi bir trend belirlenmemiş, Şanlıurfa'da ise ekim ayı hariç tüm aylarda artan yönde trend tespit edilmiştir. $\mathrm{Bu}$ artışlar nisan ayında \%5-10 aralığında kalırken, mayıs, haziran, temmuz, ağustos ve eylül aylarında ise \%10 üzerinde olmuş ve güçlü trend olarak değerlendirilmiştir. Mardin istasyonunda ise temmuz ve ağustos aylarında artan trend görülürken, eylül ayında güçlü artan trend olarak meydana gelmiştir. Yüksek buharlaşma değerlerinde Gaziantep'te haziran, temmuz ve ağustos aylarında artan trend gözlenirken, Şanlıurfa'da tüm aylarda güçlü artan trend belirlenmiştir. Mardin istasyonunda ise mayıs ayında artan trend, diğer tüm aylarda ise güçlü artan trend görülmüştür.
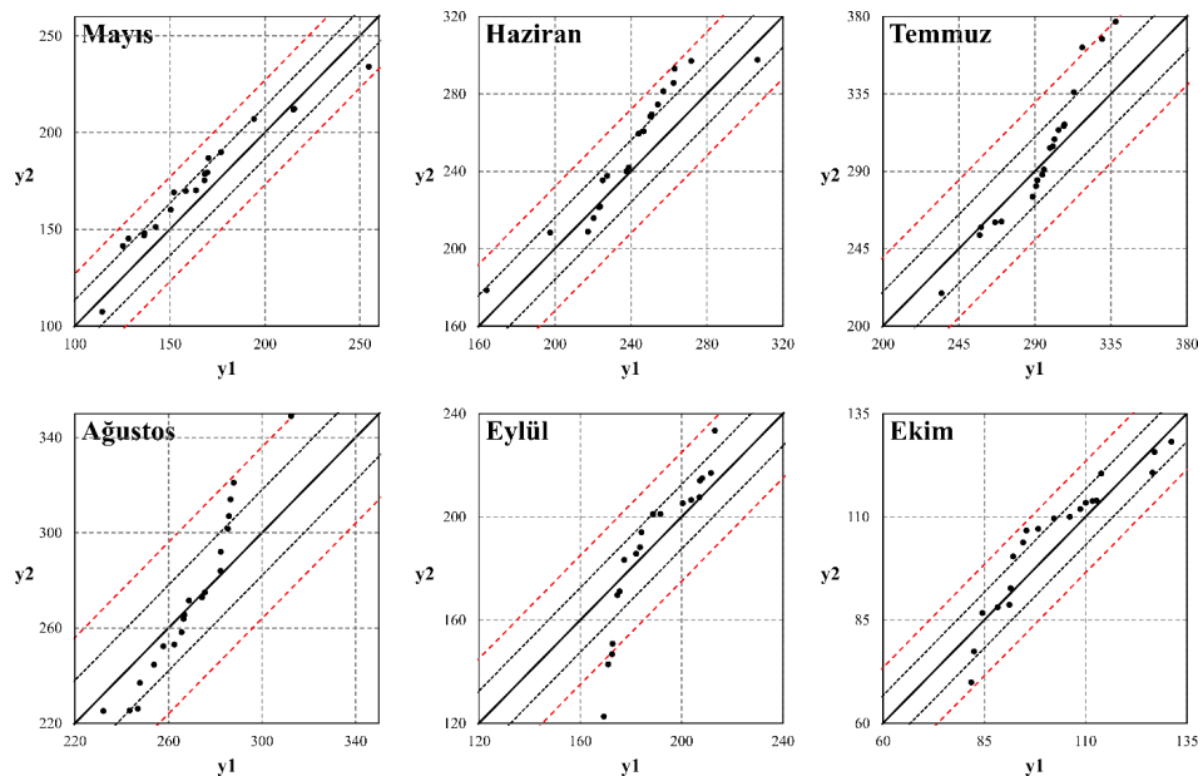

Şekil 5. ITA yöntemi sonuçları (Gaziantep istasyonu) 

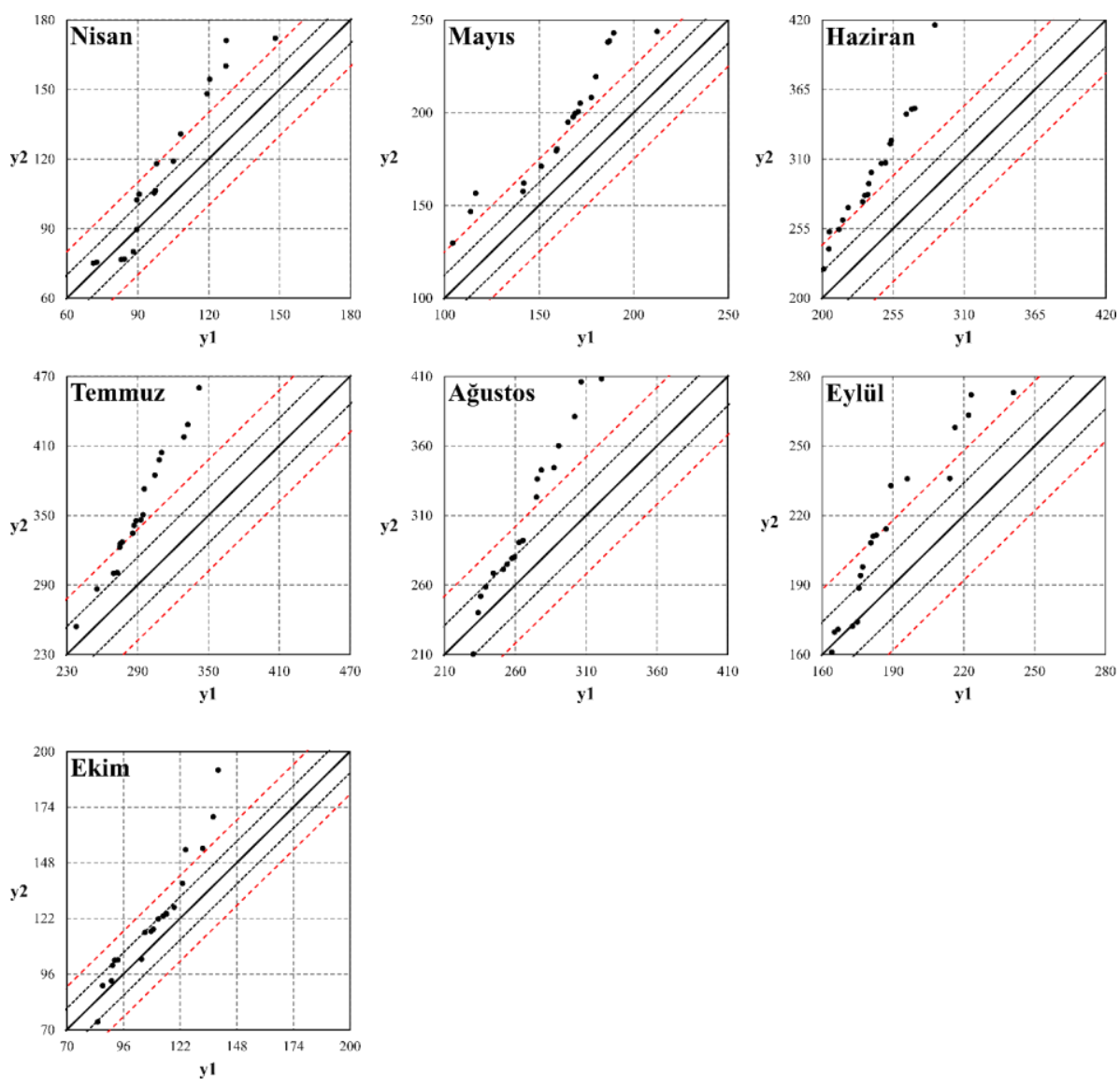

Şekil 6. ITA yöntemi sonuçları (Şanlıurfa istasyonu)
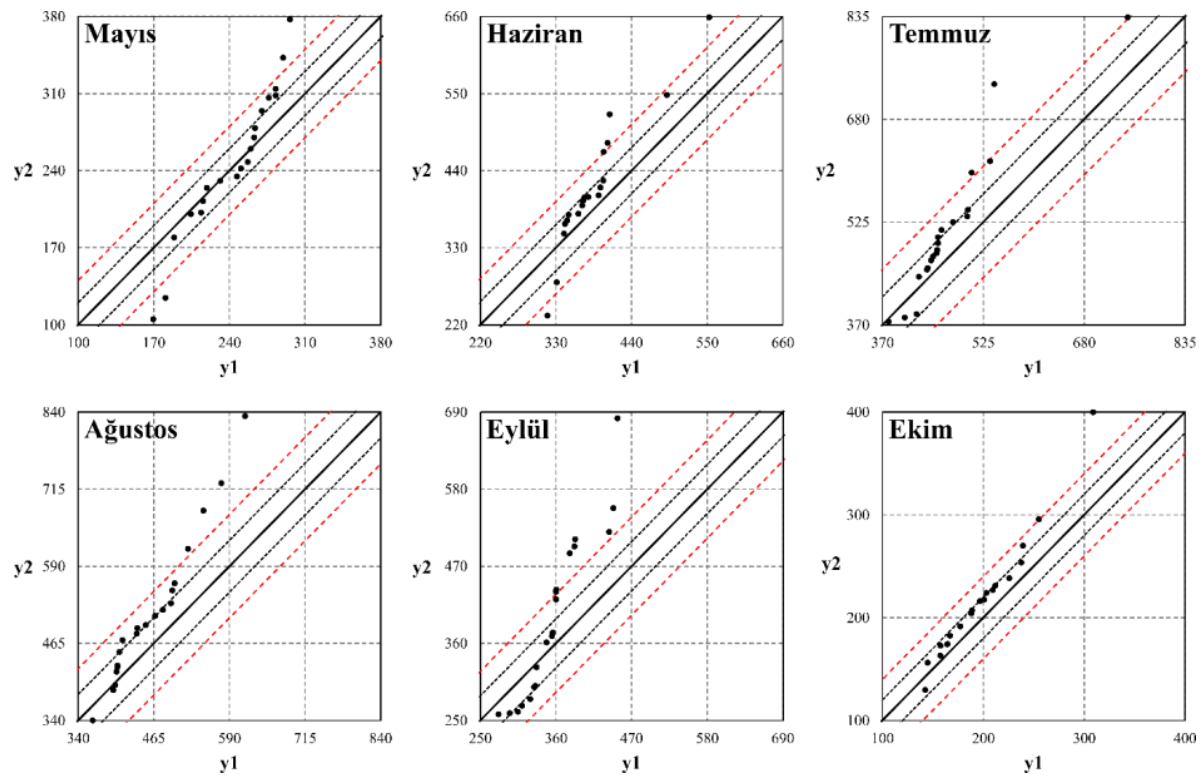

Şekil 7. ITA yöntemi sonuçları (Mardin istasyonu)

Denklem 5 ile hesaplanmış D değerleri ile MannKendall yöntemi ile hesaplanmış Z değerlerinin saçılım grafiği Şekil 8'de verilmiştir. Buna göre, iki değer arasındaki korelasyon katsayısı 0.636 olarak hesaplanmıştır. Bu değer, literatürde farklı parametreler için hesaplanmış olan $Z$ ve $D$ arasındaki korelasyon katsayıs1 ile uyumlu görülmektedir (Nisansala vd., 2020; Wu ve Qian,
2017). Ayrıca, genel olarak $Z$ ve $D$ değerleri arasında iki değer hariç işaretleri aynı olmuş, fakat özellikle MK yöntemi ile anlamlı trend belirlenen aylarda $\mathrm{D}>1.96$ durumu (\%95 güven aralığında anlamlı trend koşulu) sağlanmadığı anlaşılmaktadır. Aynı şekilde D>1.96 durumunun sağlandığı aylarda Z'nin bu şartı sağlamadığ 1 da belirlenmiş̦tir. Bunun nedeni, ITA yönteminde 
düşük, orta veya yüksek değerlerde meydana gelen trend varlığının, D değeri üzerinde etkisi olduğu değerlendirilmektedir. Ancak, D değerlerinin anlamlı monotonik trendleri belirlemede, MK yöntemi ile uyumlu olmadığı için, bu amaçla kullanımının çok uygun olmadı̆̆ değerlendirilmektedir.

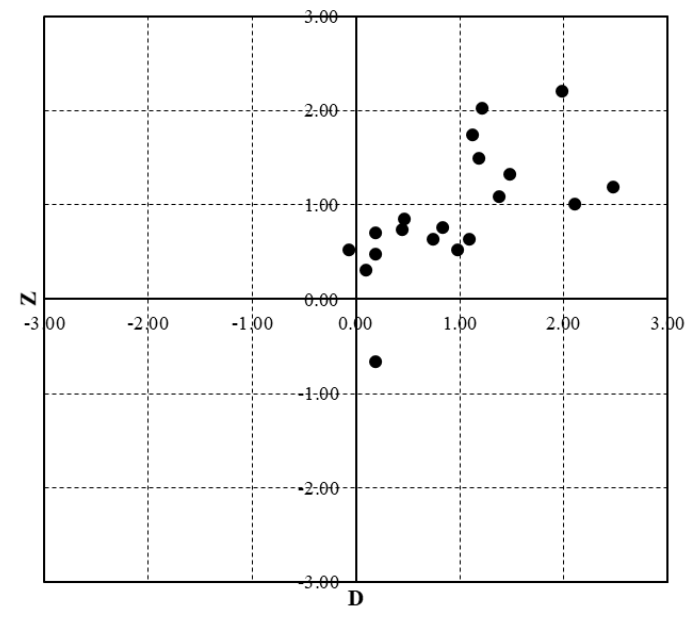

Şekil 8. Z ve D değerlerinin saçılım grafiği

$\mathrm{Bu}$ çalışmada elde edilen sonuçlar literatür ile karşılaştırıldığında, ele alınan bölge ile ilgili yapılmış olan trend analizi çalışmalarının oldukça k1sıtlı olduğu görülmüştür. Topaloğlu vd. (2012)'nin Türkiye geneline ait tava buharlaşmalarının trendini değerlendirdiği çalışmada MK testi ile Güneydoğu Anadolu Bölgesi için yapmış oldukları bölgesel trend analizi sonucunda, nisan ayında azalan, diğer aylarda ise artan yönde istatistiksel olarak anlamlı trend belirleyememiştir. $\mathrm{Bu}$ çalışma kapsamında da benzer sonuçlar elde edilmiştir, ancak ITA yöntemi ile MK testi ile anlamlı trend belirlenmemiş istasyonlarda düşük, orta ve yüksek değerlerde trend varlığına rastlanmıştır.

\section{Sonuçlar}

Güneydoğu Anadolu Bölgesi'nde yer alan Gaziantep, Şanlıurfa ve Mardin istasyonlarında ölçülmüş aylı toplam tava buharlaşma değerlerinin monotonik trendleri Mann-Kendall yöntemi ile düşük, orta ve yüksek değerlerinin trenleri ise ITA yöntemi ile belirlenmiştir. Tava buharlaşma değerlerinin lineer eğimleri Sen'in trend eğim metodu ile belirlenmiştir. Değerlendirme sonucunda;

- Ele alınan istasyon ve ayların büyük bir çoğunluğunda artan yönde bir trend tespit edilmiştir. Sadece, Mardin istasyonunda mayıs ayında ise azalan yönde bir trend tespit edilmiştir. Ancak anlamlı trend sadece Şanlıurfa istasyonunda mayıs ve eylül aylarında
$\% 95$ ve ekim ayında ise \%90 güven aralı̆̆ında artan yönde anlamlı trend varlığı belirlenmiştir.

- MK testine göre, anlamlı trend görülen Şanlıurfa istasyonunda lineer trend eğim değerlerine göre, artış miktarı mayıs ayında $\% 0.98 / y 1$, eylül ayında, \%0.72 ve ekim ayında $\% 0.53 /$ y1l şeklinde olmuştur.

- ITA yöntemi ile düşük, orta ve yüksek değerler için yapılan değerlendirme neticesinde, düşük değerler için, Gaziantep istasyonunda, eylül ayında güçlü bir azalan trend, Şanlıurfa istasyonunda mayıs, haziran ve temmuz aylarında ise artan trend, Mardin istasyonunda ise sadece mayıs ve haziran aylarında bir azalma trendi görülmüştür.

- Orta değerlere göre, Şanliurfa istasyonunda neredeyse tüm aylarda (ekim ayı hariç), Mardin istasyonunda ise temmuz, ağustos ve eylül aylarında artan trend görülürken, Gaziantep istasyonunda trend görülmemiştir.

- Yüksek buharlaşma değerlerinde, Gaziantep istasyonunda haziran, temmuz ve ağustos aylarında, Şanlıurfa ve Mardin istasyonlarında tüm aylarda artan trend görülmüştür.

MK testi ile hesaplanan $Z$ değerleri ve ITA yöntemi ile hesaplanan test göstergesi D değerleri karşılaştırılmış ve genel olarak birbirleri uyumlu oldukları, ancak D göstergesinin, monotonik trend belirleme amacıyla kullanımını durumunda $\mathrm{MK}$ 
testi ile uyumlu sonuçlar çıkarmayacağı değerlendirilmiştir.

ITA yönteminin kullanım kolaylı̆̆ı, sonuçları grafiksel olarak verme yeteneği ve istenilen değer aralığında bir trend varlığını araştırma imkânı sağlaması nedeniyle, monotonik trend belirleme yöntemlerine alternatif bir yöntem olarak değerlendirilebileceği sonucuna varılmıştır.

\section{Teşekkür}

$\mathrm{Bu}$ çalışmadaki yazarlardan Yavuz Avşaroğlu, "Sürdürülebilir Su Kaynakları" alanında YÖK 100/2000 Doktora Bursu programındadır. Yazar katkılarından dolayı YÖK'e teşekkür etmektedir.

\section{Kaynaklar}

Alashan, S. (2020). Combination of modified MannKendall method and Şen innovative trend analysis. Engineering Reports, 2(3), e12131. https://doi.org/10.1002/eng2.12131

Alifujiang, Y., Abuduwaili, J. and Ge, Y. (2021). Trend analysis of annual and seasonal river runoff by using Innovative Trend Analysis with significant test. Water, 13(1), 95. https://doi.org/10.3390/w13010095

Alifujiang, Y., Abuduwaili, J., Maihemuti, B., Emin, B. and Groll, M. (2020). Innovative trend analysis of precipitation in the Lake Issyk-Kul Basin, Kyrgyzstan. Atmosphere, 11(4), 332. https://doi.org/10.3390/atmos11040332

Arslan, O. (2019). Kapadokya Bölgesi'nin yaz ayları buharlaşma verileri için trend analizi. Niğde Ömer Halisdemir Üniversitesi Mühendislik Bilimleri Dergisi, 8(2), 948-953. https://doi.org/10.28948/ngumuh.598070

Asadi, M. and Karami, M. (2021). Modeling of relative humidity trends in Iran. Modeling Earth Systems and Environment, 1-11. https://doi.org/10.1007/s40808-021-01093-9

Ay, M. and Kisi, O. (2015). Investigation of trend analysis of monthly total precipitation by an innovative method. Theoretical and Applied Climatology, 120(3), 617-629. https://doi.org/10.1007/s00704-014-1198-8

Aydın, F. ve Topaloğlu, F. (2010). Türkiye buharlaşma verilerinin gidiş analizi. ÇÜ Fen Bilimleri Enstitüsü, 22(2), 174-184.

Bacanlı, Ü. G. ve Çukurluoğlu, S. (2018). Antalya ilinin baz1 meteorolojik verilerinin trend analizi. SETSCI Conference Indexing System, 2, 371375
Bacanlı, Ü. G. ve Tanrıkulu, A. (2017). Ege Bölgesinde buharlaşma verilerinin trend analizi. Afyon Kocatepe Üniversitesi Fen ve Mühendislik Bilimleri Dergisi, 17(3), 980-987. https://doi.org/10.5578/fmbd.66282

Bağdatlı, M. C. and Arıkan, E. N. (2020). Evaluation of maximum and total open surface evaporation by using trend analysis method in Nigde Province of Turkey. International Journal, 6(1), 138-145. https://doi.org/10.5281/zenodo.3890231

Boudiaf, B., Şen, Z. and Boutaghane, H. (2021). Climate change impact on rainfall in north-eastern Algeria using innovative trend analyses (ITA). Arabian Journal of Geosciences, 14(6), 1-18. https://doi.org/10.1007/s12517-021-06644-z

Bruton, J., Hoogenboom, G. and McClendon, R. (2000). Acomparison of automatically and manually collected pan evaporation data. Transactions of the ASAE, 43(5), 1097. https://doi.org/10.13031/2013.3002

Brutsaert, W. (1982). Evaporation into the atmosphere: Theory. History, and Applications, 1: Springer, Dordrecht. https://doi.org/10.1007/978-94-0171497-6

Burn, D. H. and Hesch, N. M. (2007). Trends in evaporation for the Canadian Prairies. Journal of hydrology, 336(1-2), 61-73. https://doi.org/10.1016/j.jhydrol.2006.12.011

Caloiero, T. (2020). Evaluation of rainfall trends in the South Island of New Zealand through the innovative trend analysis (ITA). Theoretical and Applied Climatology, 139(1), 493-504. https://doi.org/10.1007/s00704-019-02988-5

Chen, Y., Guan, Y., Shao, G. and Zhang, D. (2016). Investigating trends in streamflow and precipitation in Huangfuchuan Basin with wavelet analysis and the Mann-Kendall test. Water, $8(3)$, 77. https://doi.org/10.3390/w8030077

Çıtakoğlu, H., Geyikli, S. ve Demir, V. (2017). Ege Bölgesi yaz ayları buharlaşma verilerine trend analizi. 5. Uluslararası Katılımlı Toprak ve Su Kaynakları Kongresi

Gumus, V. (2019). Spatio-temporal precipitation and temperature trend analysis of the SeyhanCeyhan River Basins, Turkey. Meteorological Applications, 26(3), 369-384. https://doi.org/10.1002/met.1768

Hassan, A., Ismail, S. S., Elmoustafa, A. and Khalaf, S. (2018). Evaluating evaporation rate from high Aswan Dam Reservoir using RS and GIS techniques. The Egyptian Journal of Remote Sensing and Space Science, 21(3), 285-293. https://doi.org/10.1016/j.ejrs.2017.10.001 
IPCC. (2007). Climate Change 2007: Synthesis Report. Geneva: IPCC.

Jhajharia, D., Shrivastava, S., Sarkar, D. and Sarkar, S. (2009). Temporal characteristics of pan evaporation trends under the humid conditions of northeast India. Agricultural and Forest Meteorology, 149(5), 763-770. https://doi.org/10.1016/j.agrformet.2008.10.024

Jung, M., Reichstein, M., Ciais, P., Seneviratne, S. I., Sheffield, J., Goulden, M. L. And De Jeu, R. (2010). Recent decline in the global land evapotranspiration trend due to limited moisture supply. Nature, 467(7318), 951-954. https://doi.org/10.1038/nature09396

Kale, S. (2017). Analysis of climatic trends in evaporation for Çanakkale (Turkey). Middle East Journal of Science, 3(2), 69-82. https://doi.org/10.23884/mejs.2017.3.2.01

Kendall, M. G. (1948). Rank correlation methods. London: Griffin.

Kisi, O. (2015). An innovative method for trend analysis of monthly pan evaporations. Journal of hydrology, $\quad 527, \quad 1123-1129$. https://doi.org/10.1016/j.jhydrol.2015.06.009

Kuriqi, A., Ali, R., Pham, Q. B., Gambini, J. M., Gupta, V., Malik, A. and Dong, X. (2020). Seasonality shift and streamflow flow variability trends in central India. Acta Geophysica, 68(5), 14611475. https://doi.org/10.1007/s11600-02000475-4

Limjirakan, S. and Limsakul, A. (2012). Trends in Thailand pan evaporation from 1970 to 2007. Atmospheric research, 108, 122-127. https://doi.org/10.1016/j.atmosres.2012.01.010

Mann, H. B. (1945). Nonparametric tests against trend. Econometrica: Journal of the econometric society, 245-259. https://doi.org/10.2307/1907187

Menzel, L. and Bürger, G. (2002). Climate change scenarios and runoff response in the Mulde catchment (Southern Elbe, Germany). Journal of hydrology, 267(1-2), 53-64. https://doi.org/10.1016/S0022-1694(02)00139-7

Nisansala, W., Abeysingha, N., Islam, A. and Bandara, A. (2020). Recent rainfall trend over Sri Lanka (1987-2017). International Journal of Climatology, 40(7), 3417-3435. https://doi.org/10.1002/joc.6405

Nourani, V., Mehr, A. D. and Azad, N. (2018). Trend analysis of hydroclimatological variables in Urmia lake basin using hybrid wavelet MannKendall and Şen tests. Environmental Earth
Sciences,

$77(5)$,

$1-18$. https://doi.org/10.1007/s12665-018-7390-X

Oguntunde, P. G., Abiodun, B. J., Olukunle, O. J. and Olufayo, A. A. (2012). Trends and variability in pan evaporation and other climatic variables at Ibadan, Nigeria, 1973-2008. Meteorological Applications, $\quad 19(4), \quad 464-472$. https://doi.org/10.1002/met.281

Salas, J. D. (1980). Applied modeling of hydrologic time series. Colorado: Water Resources Publication.

Sandalcı, M. (2019). Sapanca Gölünde buharlaşmanın trend analizi. 4. Uluslararası Bilimsel Araştırmalar Kongresi, Yalova.

Sayyad, R., Dakhore, K. And Phad, S. (2019). Analysis of rainfall trend of Parbhani, Maharshtra using Mann-Kendall test. Econometrica, 13, 245-259.

Sen, P. K. (1968). Estimates of the regression coefficient based on Kendall's tau. Journal of the American statistical association, 63(324), 1379-1389. https://doi.org/10.1080/01621459.1968.1048093 4

Singh, D., Kumar, A., Goyal, V., Arora, M. and Allaka, N. (2020). Temporal characteristics of evaporation trends and their attribution to meteorological drivers in Roorkee (India). Authorea Preprints. https://doi.org/10.22541/au.158931107.7523740 6

Şen, Z. (2012). Innovative trend analysis methodology. Journal of Hydrologic Engineering, 17(9), 10421046. https://doi.org/10.1061/(ASCE)HE.19435584.0000556

Topaloğlu, F., Özfidaner, M. and Aydin, F. (2012). Regional trends in Turkish pan evaporation. Journal of Food, Agriculture \& Environment, 10(3\&4), 960-962.

Tosunoglu, F. and Kisi, O. (2017). Trend analysis of maximum hydrologic drought variables using Mann-Kendall and Şen's innovative trend method. River Research and Applications, 33(4), 597-610. https://doi.org/10.1002/rra.3106

TÜİK (2020). Adrese Dayalı Nüfus Kayıt Sistemi Sonuçları, 2020. Erişim adresi https://data.tuik.gov.tr/Bulten/Index?p=AdreseDayali-Nufus-Kayit-Sistemi-Sonuclari-202037210

Wu, H. and Qian, H. (2017). Innovative trend analysis of annual and seasonal rainfall and extreme values in Shaanxi, China, since the 1950s. International Journal of Climatology, 37(5), 2582-2592. https://doi.org/10.1002/joc.4866 
Yagbasan, O., Demir, V. and Yazicigil, H. (2020). Trend analyses of meteorological variables and lake levels for two shallow lakes in Central Turkey. Water, 12(2), 414. https://doi.org/10.3390/w12020414

Yenigün, K., Gümüş, V. and Bulut, H. (2008). Trends in streamflow of the Euphrates basin, Turkey. Proceedings of the Institution of Civil Engineers-
Water

Management. https://doi.org/10.1680/wama.2008.161.4.189

Yeşilırmak, E. (2013). Temporal changes of warmseason pan evaporation in a semi-arid basin in Western Turkey. Stochastic environmental research and risk assessment, 27(2), 311-321. https://doi.org/10.1007/s00477-012-0605-x 